\title{
CHARACTERISTICS OF NOCTURNAL URBAN HEAT ISLAND OF IAŞI DURING A SUMMER HEAT WAVE (1-6 OF AUGUST 2017)
}

\author{
P. ICHIM" ${ }^{1}$ L. SFICC $\breve{A}^{1}$, A. KADHIM-ABID ${ }^{2}, A . \mathrm{URSU}^{1}$, V. JITARIU $^{1}$
}

\begin{abstract}
Characteristics of nocturnal urban heat island of Iaşi during a summer heat wave (1-6 of august 2017). This paper aims to investigate in details the specific of the nocturnal urban heat island in Iaşi city area during a particular heat wave in summer time. For this, we have conducted a series of expeditionary measurements on air temperature for the interval between 1 and 6 of August 2017 which was charaterized by excessive heat conditions. Air temperature measurements were made around midnight time and were performed along westeast transects crossing the city. The main results show an intensity of $3-4^{\circ} \mathrm{C}$ for the nocturnal urban heat island of Iaşi during heat wave condition. Beside this, the structure of the urban heat island was also influenced by the atmospheric stability which enhanced the occurence thermal inversion phenomena. In these conditions more dense cold air descends on the rivers valleys generating strong cooling of $4.0-5.0^{\circ} \mathrm{C}$ in low area of the city comparatively to the city center.
\end{abstract}

Keywords: UHI, heat waves, thermal inversions, field observations.

\section{INTRODUCTION}

One of the most studied urban climate phenomenon is the "urban heat island" (UHI) effect (Hiemstra et al., 2017, Arnfield, 2003). In the last years the intrest for research of UHI in Romania is increasing (Cheval et al., 2015; Herbel et al., 2017; Sfîcă et al., 2017 a). This phenomenon is caused by the thermo-caloric specificity of different types of surfaces specific to urban centers (Shatz, 2014; Cheval, 2015). The UHI phenomenon is characterized by multitemporal variations (Oke, 2002; Schatz, 2014), becoming extremely intense and generating major socio-human problems (Herbel, 2017), especially during the warm semester of the year (Patz, 2005; Luber, 2008). The UHI is determined by a series of natural and anthropogenic factors that involve an increase in air temperature within cities from peri-urban areas (Hiemstra et al., 2017), to urban areas by anthropogenic heat released from buildings and artificial surfaces (Arnfield, 2003). Among these several factors are distinguished: high amounts of solar radiation which generates radiative heat waves especially în warm season (Sfîcă, et al., 2017 a), height regime of buildings or the albedo of anthropogenic surfaces (Cheval, 2015; Kyriakodis et al., 2017).

\footnotetext{
1"Alexandru Ioan Cuza" University of Iasi, bd-ul Carol I, nr.11, Iași, Romania; pavel_ichim@yahoo.com; sfical@yahoo.com; ursu_v_adrian@yahoo.com; vasilejitariu@yahoo.com. 2 "Gheorghe Asachi" Tehnical University of Iasi, Arhitecture Faculty, str. prof. dr. doc. Dimitrie Mangeron, nr. 3; kadhim.adriana@gmail.com
} 
So far, a detailed study has been developed for Iaşi by Sfîcă, et al. (2017 a), based on data recorded during 3 years of observation (December, 2012 to November, 2015) at 8 fixed points. The main results of this analysis revealed a large variation of the UHI phenomenon within the studied area. From a spatial point of view, Iaşi's UHI generates a mean air temperature higher than $0.8^{\circ} \mathrm{C}$ in the center of the city compared to the peri-urban area (Sfîcă et al., 2017 a). However, during the summer seasons, this phenomenon becomes very intense, especially during the night, when the air temperature in the city center is higher by $2.5-3.0^{\circ} \mathrm{C}$ compared to the periurban area (Sfîcă, et al., 2017 a). In this line, our present study aims to bring new information concerning the characteristics of Iași UHI during summer nights and especially during an intense heat waves which has affected entire Romania.

\section{STUDY AREA}

The city of Iasi is located in the north-east Romania (fig.1) with a population of approximately 300,000 inhabitants. The city of Iaşi is developed along the valley of Bahlui River and its terraces, also over hilly region that assigns the city a particular urban personality (Ursu, et. al., 2016). The largest share of population lives in the western part of the city (50\%) (Roșu and Blăgeanu, 2015), areas with a built density of exceeding 70\% (Sfîcă, et al., 2017 a).
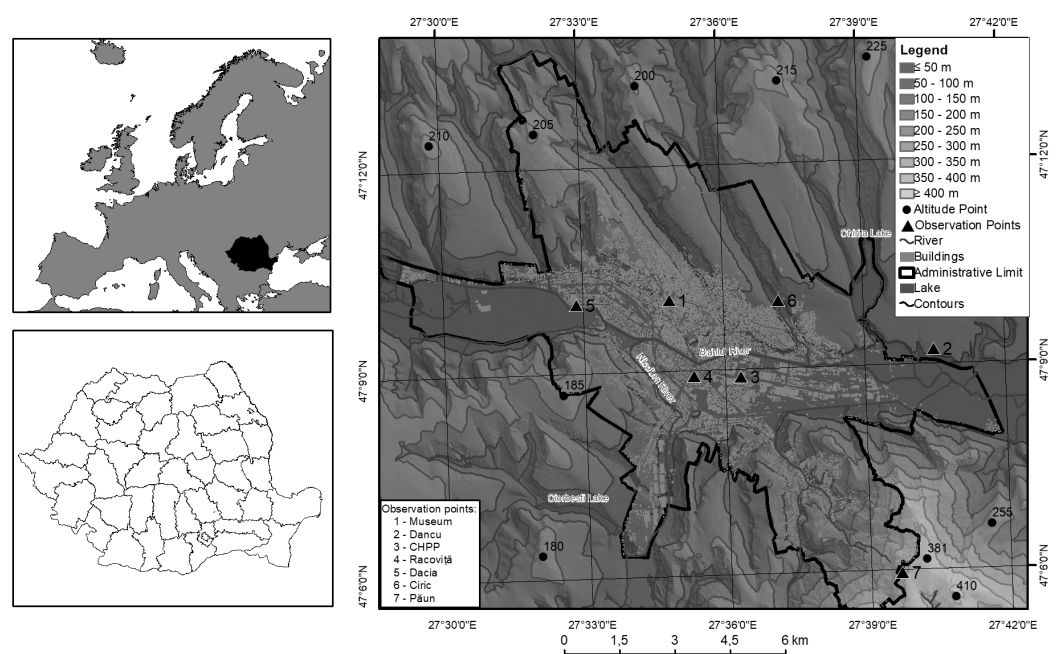

Fig. 1. Phisico-geographical position and hypsometric characteristics of Iasi city

\section{SYNOPTIC CONDITIONS}

The heat wave was delimited on the basis of $32{ }^{\circ} \mathrm{C}$ threshold of daily air maximum temperature which corresponds to a threshold which is used widely in the United States to define summer hot days (Enscore et al., 2002). According to Global Summary of the Day from NOAA (Climate Prediction Center, 1987), in the 
period between 1 and 6 of August 2017 the maximum daily air temperature at official Iaşi-SYNOP weather station has exceeded this threshold. The maximum intensity of the heat-wave was recorded oficially on 5 of August which corresponded with the maximum 2017 summer air temperature in Iaşi $\left(37.8{ }^{\circ} \mathrm{C}\right)$. The data from the urban network of air temperature monitoring in Iaşi, described in Sfícă et al. (2017a), indicated a maximum of $39.9^{\circ} \mathrm{C}$ in the low, industrial region of the city on 6 of August, just before the cold front arrival which ended the heat wave in the same day. The minimum daily temperature has increased from $15.8{ }^{\circ} \mathrm{C}$ on the first day of the heat wave to $21.2{ }^{\circ} \mathrm{C}$ in the last day of the heat-wave.

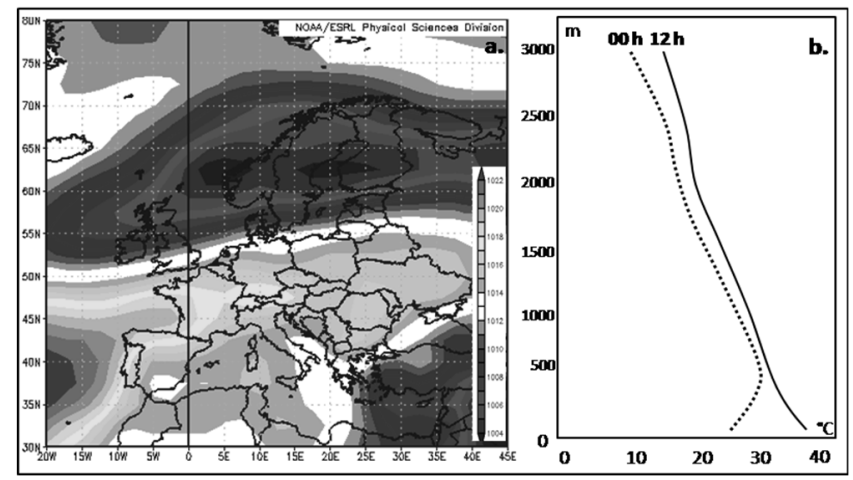

Fig. 2 Composite sea level pressure map (a) at european scale for 1-6 of August 2017(NCEP/NCAR data base) and temperature profile (b) for midday (00 $h$ ) and midnight (12 h) on lower troposphere for 4 of August 2017 in the region of Iaşi city (adapted from Global Forecast System via tropicaltidbits.com)

From synoptically point of view, taking to consideration the composite map of sea level pressure (fig. 2 a) from NCEP/NCAR data base (Kalnay et al., 1996), this heat wave could be assigned to anticyclonic type according to the criteria presented in Sfícă et al. (2017b). A strong ridge of the Azores anticyclone, which was developed inside the Europe, advected tropical air masses across the southern part of the continent. Very specific for this heat wave was the strong temperature inversion observed during the night below $400 \mathrm{~m}$ of altitude (fig. $2 \mathrm{~b}$ ). This aspect rendered the highlighting of nocturnal urban heat island more difficult.

\section{DATA AND METHODS}

Air temperature measurements were performed with a Lutron thermocouple data-logger installed inside a solar screen at the end of a plastic stem at a standard height of $2 \mathrm{~m}$. Measurements were made by car along transects from the peri-urban area to the center of the city. In this way, the city was crossed by several transects (fig. 3).

All measurements started and ended at the same point between 23 PM and $1 \mathrm{AM}$. Based on the temperature difference from the starting point between the first and the last observation a temperature gradient per minute was calculated.This 
temperature gradient was applied to each value collected depending on its point of observation. For instance, for a point for which the data was collected 20 minute after the start of the transect its values were corrected with the temperature variation resulted from the temperature gradient along the transect for that day. In this way, corrected temperature values were obtained regardless of the temporal variation of temperature during the 2 hours of observation. In this way we have obtained a clear image of spatial distribution of air temperature inside the city.
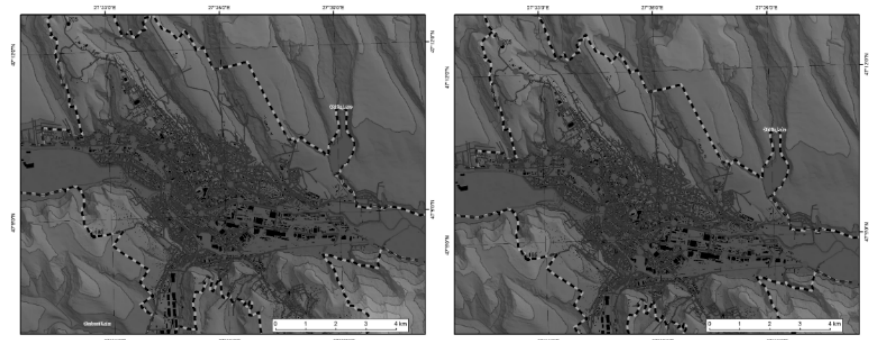

Fig. 3 Field observations points:01-02.08.2017 (left), 03-06.08.2017 (right)

For spatial distribution of air temperature we used residual kriging method (Patriche, 2009). This method represent better the air temperature distribution and air temperature anomalies (UHI or thermal inversion phenomena), influenced by the altitude variation (Sfîcă, et. al., 2017 a).

\section{DISCUSSION}

During the observation period (1-6 of August 2017) the mean air temperature as indicated by the classical temperature observation network installed in Iași showed a variation between $29.4^{\circ} \mathrm{C}$ recorded at CHPP station and $27.5^{\circ} \mathrm{C}$ at Păun station (tab. 1). The daily mean air temperature values recorded during the heat wave period revealed a mean thermal gradient of only $0.3^{\circ} \mathrm{C} / 100 \mathrm{~m}$, which reflects the stable air stratification mentioned above. From the distribution of the recorded mean air temperature we can see a similar behaviour of the UHI described by Sfîcă et. al. (2017 a).

Besides these general features, our transects have revealed some important aspects $\mathrm{du}$ to their higher resolution. The topographic complexity specific to Iaşi city gives the urban climate a series of discontinuities regarding the distribution of air temperature values.

A series of thermal asymmetries are revealed in the UHI pattern distribution, distinguishing themselves as urban areas with high temperature values. These urban spots are represented by surfaces with predominantly artificial areas such as Trainstation area, combined heat power plant (CHPP), Iulius Mall area (fig. 4) where the temperature was $3-4^{\circ} \mathrm{C}$ higher than in Tomesti village (periurban area). In urban areas with a high build-up ratio, the air temperature at $23^{00}$ always reached the maximum value (fig. $4 \&$ fig. 5 ). These values indicate that the 
nocturnal UHI which is known to be more intense in summer (Sfîcă et al., 2017 b) is actually the most intense during the summer heat waves.

Table. 1. Mean air temperature between 01 - 06 August 2017 and air temperature values

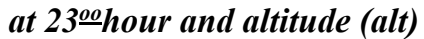

\begin{tabular}{|c|c|c|c|c|c|c|c|c|c|c|c|c|c|c|}
\hline \multirow[t]{2}{*}{ days } & \multicolumn{2}{|c|}{$\begin{array}{l}\text { 1. Museum } \\
68 \mathrm{~m} \text { alt }\end{array}$} & \multicolumn{2}{|c|}{$\begin{array}{l}\text { 2. Dancu } \\
59 \mathrm{~m} \text { alt }\end{array}$} & \multicolumn{2}{|c|}{$\begin{array}{l}\text { 3. CHPP } \\
40 \mathrm{~m} \text { alt } \\
\end{array}$} & \multicolumn{2}{|c|}{$\begin{array}{l}\text { 4. Racoviță } \\
43 \text { m alt } \\
\end{array}$} & \multicolumn{2}{|c|}{$\begin{array}{l}\text { 5. Dacia } \\
42 \mathrm{~m} \text { alt }\end{array}$} & \multicolumn{2}{|c|}{$\begin{array}{l}\text { 6. Ciric } \\
48 \mathrm{~m} \text { alt }\end{array}$} & \multicolumn{2}{|c|}{$\begin{array}{l}\text { 7. Păun } \\
334 \text { m alt }\end{array}$} \\
\hline & mean & $23^{\circ}$ & ean & $23^{o o}$ & ean & $23^{o}$ & mean & 23 & mean & $23^{o o}$ & ean & $23^{o o}$ & nean & $23^{o o}$ \\
\hline & 26,9 & & & 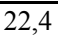 & 7 & 25,2 & 267 & & 260 & 25, & & 27 & 26 & 27 \\
\hline$\theta_{2}$ & 28,3 & 26 , & 0 & 24, & ,0 & 27,3 &, 0 & 26 & 8 & 26 & & 26 & 7,4 & 24,3 \\
\hline 03.08. & 28,4 & 27, & 7,8 & 25,1 & 1 & 27 & 27,9 & 27 & 28,3 & 25 & & 2 & 27,5 & 24,3 \\
\hline 04.08. & 29,5 & 27,9 & 29,2 & 25,2 & 0,6 & 27,9 & 9,1 & 27 , & 9,4 & 26 & 0 & 25,1 & 0 & 24,8 \\
\hline 05.08. & 30,3 & 28,8 & 29,8 & 25,5 & 31,5 & 28,6 & 30,1 & 28,4 & 30,1 & 26,6 & 29,6 & 25 , & 29,4 & 25,2 \\
\hline 06.08. & 27,7 & 22,5 & 27,7 & 22,3 & 28,4 & 23 & 27,6 & 22,6 & 27,4 & 22,9 & 27,5 & 22,2 & 26,5 & 20,4 \\
\hline Avg. & 28,5 & 26,5 & 28,2 & 24,1 & 29,4 & 26,6 & 28,2 & 26,1 & 28,3 & 25,6 & 28,0 & 24,0 & 27,5 & 23,6 \\
\hline
\end{tabular}

Thermal asymmetries are distinguished also at the confluence of left affluents of Bahlui River, such as the valleys of Ciric or Botanica rivers. Along their valleys, the slightly cooler air will descends in the first part of the night from upper hills from north of the city towards its center. Thus, mean air temperature will also decrease in these areas, by about $1.5^{\circ} \mathrm{C}$, as in the case of the BahluiBotanica confluence area and $1.6^{\circ} \mathrm{C}$ in the Ciric valley (fig. 4).

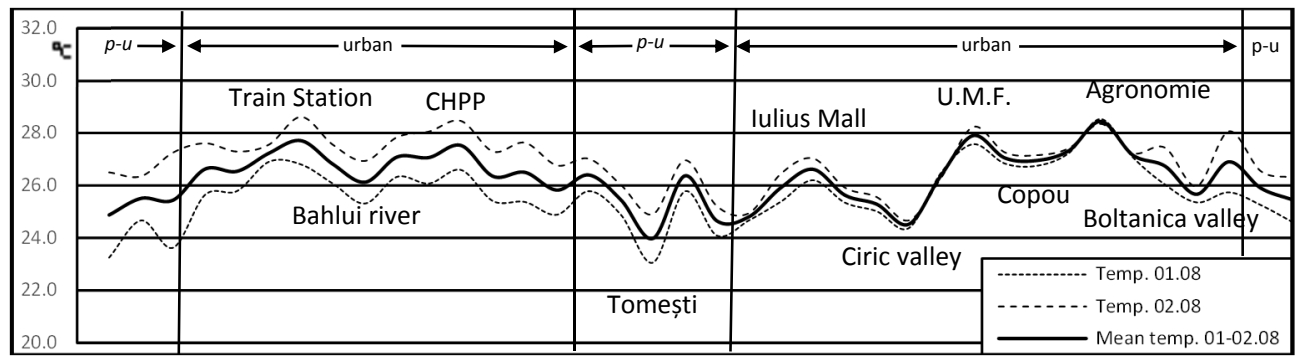

Fig. 4Air temperature cross-section in Iasi City 01 - 02 August 2017 at $23^{\text {oo }}$ hour in urban and peri-urban area $(p-u)$

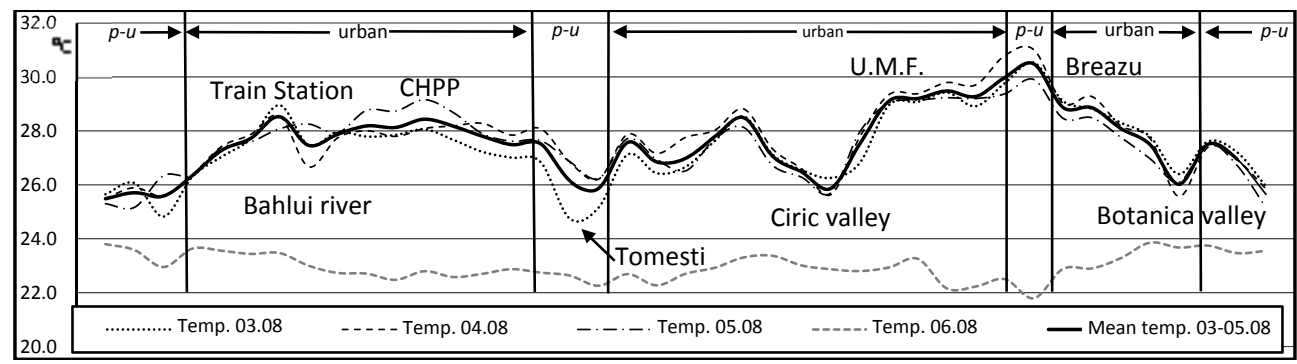

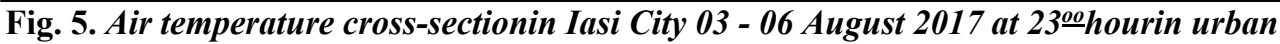
and peri-urban area $(p-u)$

In the vertical profile, based on data from air temperature measurements during the 6 days of observations, it can be seen how hot air volumes are correlated with altitude as a result of temperature inversion. For the interval 01-05.08.2017 at 
$23^{00}$ (fig. 6. b), due to the above mentioned characteristics of the heat wave, a strong thermal inversions was installedon the lower altitude (100-300 m). For this reason, along our transects the highest air temperature were recorded in the higher part of the city (Copou area), while in the lower areas, especially at the confluence areas the lowest temperature values have occured (fig. 6).
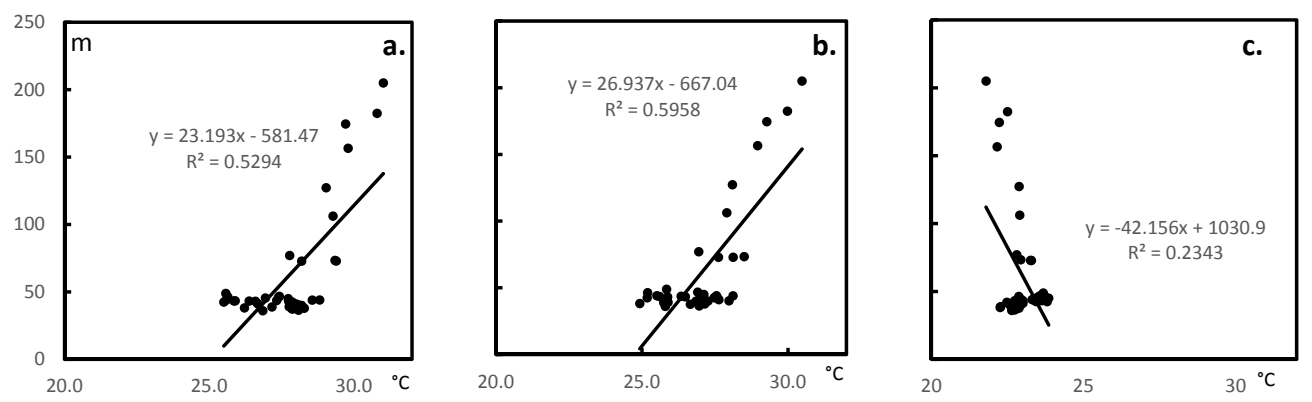

Fig. 6. Conection betweenaltitude and air temperature at 23 PM;

a. 04.08.2017; b. mean temperature (01-05.08.2017); c. 06.08.2017

Above that, thermal inversions in the city of Iaşi have a fairly high frequency. Ichim et. al., (2014), observed that the thermal inversions measured at 23:00 have a frequency of approx. 31\% within the city of Iasi. This way the nocturnal effect of the urban heat island (Bornstein, 1968) is shaped by the descending cold air upon valleys and the rise of the hot air generated by the UHI (fig. 6. a, b).

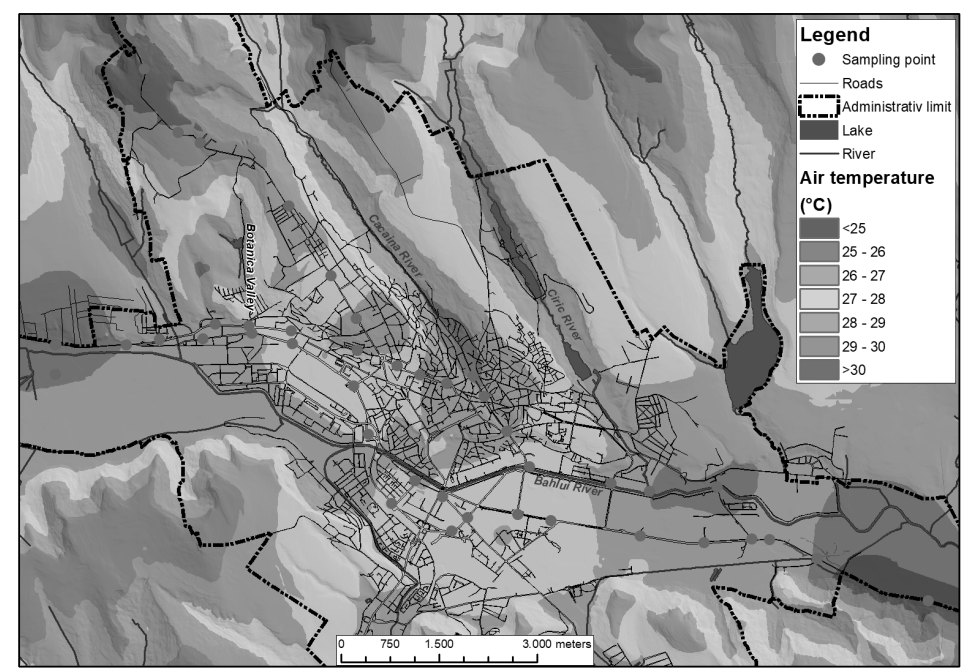

Fig. 7. Spatial distribution of the mean temperature value in Iași (01-05 August, 23 $\left.{ }^{\circ o}\right)$

The observations from the last day of the heat wave (August 6, 2017), were performed under mild atmospheric instability and moderate rainfall, after a day with air temperatures that until $23^{00}$ (observation start time) were close to mean 
values of the previous days. Under these circumstances, even if the air temperature observations tend to balance, the UHI effect is accentuated in the low-areas of Iaşi urban area (fig. 6. f.), where the air temperature values are with $0.5-1{ }^{\circ} \mathrm{C}$ higher.

It is known that during summer UHI has the higest intensity, especially during the night with differences of $2.5-3.0^{\circ} \mathrm{C}$ between urban and peri-urban area with UHI boundary layer well-defined in the urban area (Sfícă et. al. 2017 a). From the present analysis, a difference of $3.0-4.0^{\circ} \mathrm{C}$ between urban and peri-urban areas (fig.7) was observed which confirms that the night summer heat island is fueled by intense heat waves. The spectacular difference is specific inside the urban area, where Ciric Valley generated the strongest cooling that is similar with "cliff" efect described by Oke, 2002 between rural and peri-urban regions. In this conditions, temperature difference between the bottom of the valley and the top of the terrace being of $3.3^{\circ} \mathrm{C}$. For the analyzed period (fig. 7), two coresof UHI are distinguished with different intensities. A low altitude core centred above Bahlui floodplains that covers especialy the industrial area of the city and the second core is centred on the upper terraces of the Bahlui River, which extends at the base of Copou hill.

\section{CONCLUSIONS}

An intensity of $3-4^{\circ} \mathrm{C}$ of nocturnal UHI during this heat wave was observed during the five days of field observations which confirms the role of heat waves for the intensification of nocturnal heat island in summer.

Measured values at sites might show large variation because of the influence of micro-variations of the immediate environments. Measured temperature values can be affected by advective effects from the wider environment especially at night. Thermal inversion phenomena generates an altitude shift of UHI occurrence overnight in conditions of atmospheric stability, dividing the core of UHI into two spots. Another peculiarity of the heat wave analyzed here is given by the strong thermal inversion which rendered the higher area of the city (Copou) the most warmer area in the city around midnight.

Acknowledgement: A"This work was supported by a grant of the "Alexandru Ioan Cuza" University of Iasi, within the Research Grants program, Grant UAIC, code GI-UAIC2017-05"

\section{REFERENCES}

1. Arnfield, A. J. (2003), Two decades of urban climate research: a review of turbulence, exchanges of energy and water, and the urban heat island.International journal of climatology, 23(1), 1-26

2. Cheval, S., Dumitrescu, A. (2014), The summer surface urban heat island of Bucharest (Romania) retrieved from MODIS images. Theoretical and Applied Climatology, DOI 10.1007/s00704-014-1250-8

3. Bornstein, R. D., (1968), Observations of the Urban Heat Island Effect in New York City, American Meteorological Society, https://doi.org/10.1175/15200450(1968)007<0575:OOTUHI>2.0.CO;2 
4. Enscore, R., Biggerstaff, B., Brown T., Fulgham, R., Reynolds, P., Engelthaler, D., Levy, C., Parmenter, R., Montenieri, J., Cheek, J., Grinnell, R., Ettestad, P., Gage, K. (2002), Modeling relationships between climate and frequency of human plague cases in the southwestern united state, 1960-1997. Am. J. Trop. Med. Hyg., 66 (2), pp. 186-196.

5. Herbel, Ioana, Croitoru, Adina-Eliza, Rus, Adina Viorica, Roşca, Cristina Florina, Harpa, Gabriela Victoria, Ciupertea, A. F., Rus I. (2017), The impact of heat waves on surface urban heat island and local economy in Cluj-Napoca city, Romania. Theoretical and Applied Climatology, DOI 10.1007/s00704-017-2196-4

6. Hiemstra, J.A., Saaroni, H., Amorim, J.H. (2017), The Urban Heat Island: Thermal Comfort and the Role of Urban Greening. In: Pearlmutter D. et al. (eds) The Urban Forest. Future City, vol 7. Springer, Cham

7. Ichim, P., Apostol, L., Sfîcă, L., Kadhim-Abid, Adriana-Lucia, Istrate, V. (2014), Frequency of thermal inversions between Siret and Prut rivers in 2013, Present Environment \& Sustainable Development, Vol. 8, no. 2, Iași, doi: 10.2478/pesd2014-0040

8. Kalnay, E. (1996), The NCEP/NCAR 40-year re-analysis project. Bull Am Meteorol Soc 77(3):437-471

9. Kyriakodis, G-E., Santamouris, M. (2017), Using reflective pavements to mitigate urban heat island in warm climates - Results from a large scale urban, Urban Climate, http://dx.doi.org/10.1016/j.uclim.2017.02.002

10. Luber, G., McGeehin, M. (2008), Climate Change and Extreme Heat Events, American Journal of Preventive Medicine, Volume 35, Number 5, doi:10.1016/j.amepre.2008.08.021

11. Patz, J.A., Campbell-Lendrum, D., Holloway, T., Foley, J.A. (2005), Impact of regional climate change on human health, doi:10.1038/nature04188

12. Oke, T.R. (2002), Boundary layer climates. Routledge.

13. Roșu L, Blăgeanu, A. (2015), Evaluating performances of a public transport network in a post-socialist city using quantitative spatial approach. Urbani Izziv 26(2):103-116. https://doi.org/10.5379/urbani-izziv-en-2015-26-02-002

14. Schatz, J., Kucharik, C. J. (2014), Seasonality of the Urban Heat Island Effect in Madison, Wisconsin, American Meteorological Society, https://doi.org/10.1175/JAMC-D-14-0107.1

15. Sfîcă, L., Ichim, P., Apostol, L., Ursu, A. (2017 a.), The extent and intensity of the urban heat island in Iasi city, Romania, Theoretical and Applied Climatology, DOI: $10.1007 / \mathrm{s} 00704-017-2005-4$

16. Sfî̀ă, L., Croitoru, Adina-Eliza, Iordache, I., Ciupertea, A.F. (2017 b.), Synoptic Conditions Generating Heat Waves and Warm Spells in Romania, Atmosphere 2017, 8(3), 50; doi:10.3390/atmos8030050

17. Ursu, A., Andrei, M., Chelaru, D.A., Ichim, P. (2016), Built-up area change analysis in Iasi city using GIS, Present Environment and Sustainable Development, Volume 10, no.1, 2016, DOI 10.1515/pesd-2016-0018.

18. *** Climate Prediction Center/National Centers for Environmental Prediction/National Weather Service/NOAA/U.S. Department of Commerce (1987) CPC global summary of day/month observations, 1979-continuing. Research Data Archive at the National Center for Atmospheric Research, Computational and Information Systems Laboratory, Accesed 15 Feb 2018. 